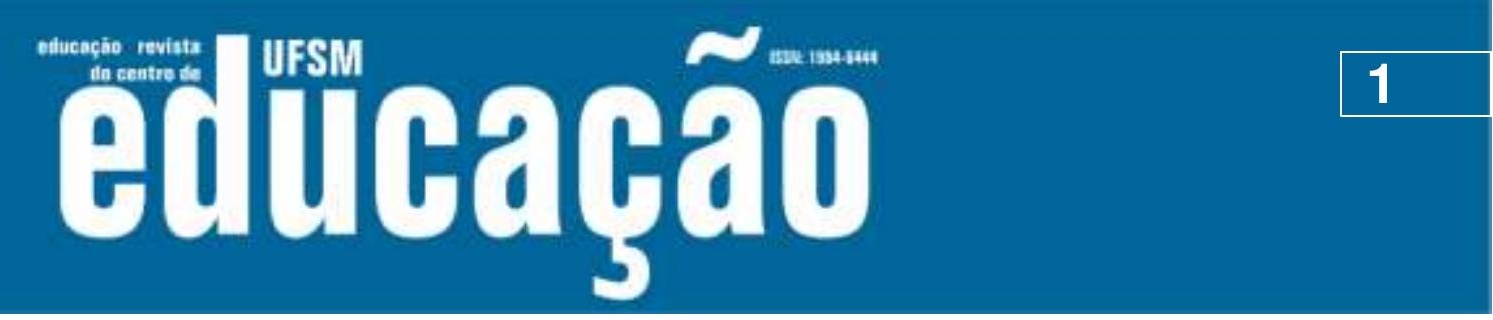

ISSN: 1984-6444 | http://dx.doi.org/10.5902/1984644433823

\title{
Ecopercepções: representações sociais da natureza no universo infantil
}

\author{
Ecoperceptions: social representations of nature in the children's \\ universe
}

Daniela Santos Silva
Instituto Federal de Educação, Ciência e Tecnologia Baiano

Juracy Marques dos Santos

Universidade do Estado da Bahia

\section{RESUMO}

Este artigo trabalha aspectos da natureza humana infantil. A criança apresenta as reminiscências da construção da personalidade do homem, tonicidades que vão evoluindo ao longo da vida e que podem ser pensadas em suas representações. Este estudo reúne resultados parciais da pesquisa de mestrado em Ecologia Humana e Gestão Socioambiental (PPGECOH-UNEB), e tem como objetivo investigar as representações da Natureza, a partir da percepção ambiental infantil no contexto escolar no munícipio de Juazeiro-BA, analisando e descrevendo a linguagem da criança, a partir do aporte teórico das Representações Sociais. Metodologicamente, realizamos observações participantes, anotações no diário de campo, oficinas de mapas mentais e entrevistas sobre os desenhos e sobre a concepção de Natureza na ótica infantil. Os resultados apresentaram uma visão Ecoperceptiva da Natureza, as crianças revelam elementos imersos em reflexões que versam sobre as ações antrópicas no meio ambiente, ressaltando a mística vinculada a essência da vida, num elo profundo de cuidado, afeto e respeito à Natureza.

Palavras-chave: Ecologia humana; Meio ambiente; Criança.

\section{ABSTRACT}

This article deals with aspects of the human nature of children. The child presents the reminiscences of the construction of the personality of the man, tonicities that evolve throughout the life and that can be thought in its representations. This study brings together partial results of the master's research in Human Ecology and SocioEnvironmental Management (PPGECOH-UNEB), and aims to investigate the representations of Nature, based on children's environmental perception in the school context in the municipality of Juazeiro-BA, analyzing and describing the language of the child, based on the theoretical contribution of the Social Representations. Methodologically, we make participant observations, notes in the field diary, mental map workshops and interviews about the drawings and the conception of Nature in the children's perspective. The results presented an Ecoperceptiva vision of Nature, the children reveal elements immersed in reflections that deal with the anthropic actions in 


\section{Lusm outibarato

ISSN: 1984-6444 | http://dx.doi.org/10.5902/1984644433823

the environment, highlighting the mystique linked to the essence of life, in a deep bond of care, affection and respect for Nature.

Keywords: Human ecology; Environment; Child.

\section{Introdução}

A escrita deste artigo está vinculada a reflexões teóricas e empíricas, que floresceram, a partir de questionamentos imersos na essência da percepção e da representação infantil sobre a Natureza. Freud, o precursor da Psicanalise, definiu a base conceitual da personalidade humana advinda das raízes infantis, concebendo que, "a mais profunda e eterna natureza do homem, em cuja evocação nos seus ouvintes o poeta está acostumado a confiar, reside nos impulsos da mente que têm suas raízes numa infância que desde então se tornou pré-histórica" (FREUD, 1900, p. 221). Assim, podemos inferir que nos ecossistemas do inverso infantil está os sistemas que evoluíram para a ação adulta.

A infância é ascendente na construção da personalidade humana, suas raízes concentram o início da evolução do homem e da mulher, e estão intimamente vinculadas ao organismo natural. A criança tonifica seus pensamentos associados aos elementos da Natureza, experiências delineadas num conjunto de projeções e ações, interiores e exteriores ao ambiente. Ao nos concentramos nessa relação, algumas indagações foram afloradas, originando no questionamento primordial desta pesquisa: Quais as Representações Sociais da Natureza no universo infantil a partir do contexto escolar?

Na obra Alfabetização Ecológica: a educação das crianças para um mundo sustentável, o físico austríaco Fritjof Capra, desencadeia uma discussão acerca da educação ecológica, reflexões principiadas nos aspectos ecológicos, pautado no respeito pela Natureza, concentrado numa abordagem multidisciplinar. A educação está presente no contexto social, assim como outros espaços, a escola também é um ambiente de aprendizagens, de partilha de conhecimentos que se conectam a diversos modos de vida. Segundo Capra, "a educação para a vida sustentável estimula tanto o entendimento intelectual da ecologia como cria vínculos emocionais com a natureza" (CAPRA, 2006, p. 15). 


\section{Autuaŗão}

ISSN: 1984-6444 | http://dx.doi.org/10.5902/1984644433823

A articulação do ambiente acontece de maneira integrada, às estruturas estão interligadas umas às outras, organismos se cruzam num conjunto de fenômenos em desenvolvimento. Lançar nossos olhares, frente a um tempo em que a construção do conhecimento, é algo que acontece num fluxo continuo, nos faz pensar uma educação construída a partir dos elementos que estão dentro e fora dos muros escolares, é uma reflexão que insere nesse processo os saberes naturais. Nesse sentido, é de suma importância pensar o desenvolvimento da educação ambiental desde os primórdios da humanidade, a infância é uma etapa importante da vida, período de afloramento e consolidação de descobertas, manifestação de novas capacidades, face às relações estabelecidas entre a sociedade e o ambiente.

A Terra, grande esfera viva, habita os fluidos desse universo gigantesco e misterioso, na pupila dos sentidos infantis, e é refletida nas percepções da imensidão de vidas que habitam o cosmo, antes como crianças, depois adultos. O universo se mantém através de múltiplas conexões, tudo isso envolve fatores físicos, biológicos, orgânicos e inorgânicos, ligados pela essência de diversas formas de vida que flutuam no espaço da existência.

Nessa direção, no século XX nasce a Ecologia Humana, ciência que estuda a relação do homem-mulher com o meio ambiente, imerge na multidimensão das relações estabelecidas com o planeta. Essa ciência tem uma de suas raízes na Escola de Chicago, cujo marco conceitual dista de 1936, atribuído pelo estudioso Robert Ezra Park, com a publicação do artigo intitulado Human Ecology in The American Journal of Society, estudo que versava sobre o comportamento humano no ambiente urbano nos Estados Unidos (PARK, 1936).

Segundo Park a Ecologia Humana "é uma tentativa de aplicar às inter-relações dos seres humanos, um tipo de análise aplicado anteriormente às inter-relações de plantas e animais" (PARK, 1945, p. 37). Vale ressaltar que essas postulações refletem na relação da Ecologia Humana com a Ecologia Vegetal e Animal, remete ao vinculo embrionário da espécie humana ao organismo da Natureza.

Há teorias sobre a origem da Ecologia Humana que vão em outra direção. Marques (2017), no seu livro A Ecologia de Freud: Os Ecossistemas da Natureza Humana, defende que Freud foi um dos primeiros pesquisadores a estruturarem um 


\section{Us: Allotato

ISSN: 1984-6444 | http://dx.doi.org/10.5902/1984644433823

paradigma multirreferencial para o estudo da espécie humana, conferindo a Psicanálise, e diria, à infância humana, um lugar de destaque na epistemologia desse campo de conhecimento.

Pensar esses aspectos influi na reflexão acerca dos sujeitos dessa pesquisa. Dessa forma, a composição teórica deste artigo está embasada na Representação Social, campo de estudo vinculado a Psicologia Social, que tem como precursor o psicólogo romeno Serge Moscovici, que concentrou seus estudos na Representação Social da Psicanalise, pela população parisiense. No entanto, o subsidio inicial foi desencadeado pelas conceituações do sociólogo francês Emille Durkheim, que cunhou o termo "representação coletiva", buscando caracterizar pensamento social e pensamento individual (MOSCOVICI, 1978).

Segundo Moscovici, a Representação Social "é a organização de imagens e linguagem, porque ela realça e simboliza atos e situações que nos são e o uso nos tornam comuns" (MOSCOVICI, 1978, p. 25). Nesse universo, a exposição do pensamento está concentrada no fluxo de imagens do consciente e inconsciente social, os elementos imagéticos da mente, são evocados pelos fatores internos e externos ao ambiente.

Ao falar de percepção, representações, linguagens do pensamento infantil, permeamos as imagens do interior humano, essa reflexão nos permite cogitar quão singular e plural é a composição da vida. A criança percorre suas percepções ambientais a partir do simbolismo, o modo pelo qual refletem o organismo existencial planetário, propõe uma imersão que flutua de maneira sublime, face do tempo e do espaço. Nessa perspectiva, descrevemos aqui, alguns resultados da pesquisa sobre as Representações Sociais da Natureza, a partir da percepção ambientais infantis no contexto escolar no munícipio de Juazeiro-BA.

\section{A Natureza das Representações Sociais}

As Representações Sociais são organismos que comunicam as expressões da mente, possibilitando a reflexão das raízes imagéticas do pensamento. Como dito anteriormente, o sociólogo Émile Durkheim foi o precursor da definição "representação 


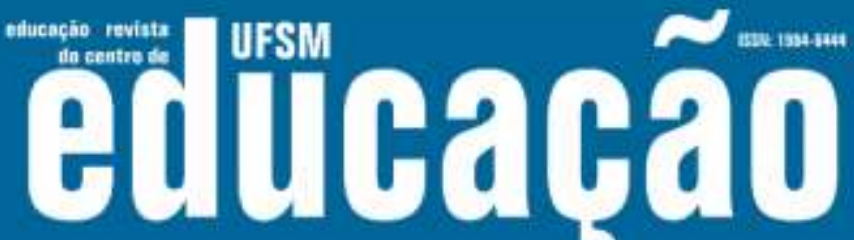

ISSN: 1984-6444 | http://dx.doi.org/10.5902/1984644433823

coletiva", projetando o termo no âmbito sociológico, sua premissa faz referência às inúmeras atividades cognitivas, no âmbito individual e social (MOSCOVICI, 1978).

O termo représentation já era bem difundido na França, desde o século XIII, porém, sua polissemia apresentava inúmeros significados, "referindo-se a várias atividades da mente, como produção de imagens, símbolos e sinais, como também demonstrações gráficas, isto é, coordenadas cartesianas e imitações" (MARKOVÁ, 2006, p. 170).

Para o psicólogo britânico, Ivana Marková, as considerações de representações são como "pensamentos em movimento" e na concepção de Serge Moscovici, "a représentation é sempre direcionada aos outros: através do ato de apontar alguma coisa à alguém, ela fala; e através do ato de expressar algo a alguém, ela se comunica" (MOSCOVICl, 1978, p. 26). São elementos que trazem a tona o semblante dos pensamentos e a compreensão dos seus artefatos.

Marková afirma, "as representações não são reflexos passivamente produzidos na natureza, mas sim ativamente construídas através da experiência" (2006, p. 174). As representações revelam os sistemas interiores, advindos das ramificações cognitivas em contato com as experiências vivenciadas com o ambiente, é um intercâmbio de saberes entre o homem e a Natureza. De acordo com Pickering "as representações são geradas coletivamente na vida social. Elas são a chave ao conhecimento, à lógica e ao entendimento do ser humano" (2000, p. 12). São linguagens produzidas nas relações com o meio, imagens concebidas no pensamento e externalizadas na atmosfera da realidade.

O psicólogo suíço, Jean Piaget, postulou em seus escritos à teoria do desenvolvimento infantil, descrevendo os estágios de desenvolvimento numa reflexão evolutiva da infância. Os estudos de Piaget também definiram conceitos como "acomodação, assimilação e equilíbrio", discutindo a representação do mundo infantil (PIAGET, 2005). O pensamento de Piaget possibilitou reflexões às concepções de Moscovici, onde, a partir das categorizações da psicologia da criança, enraizadas nas descobertas piagetianas cogitou o incremento desse conhecimento na teoria das Representações Sociais. 


\section{THEM entuará}

ISSN: 1984-6444 | http://dx.doi.org/10.5902/1984644433823

O amadurecimento humano se dá desde a fase infantil, como afirmou o próprio Freud, é um processo continuo e holístico que habita as nuances da personalidade humana, carrega as impressões ancestrais da anatomia do corpo e da alma do homem e da mulher. "Assim pudemos confirmar, o que já suspeitávamos, a extraordinária importância que para toda a orientação posterior do homem têm as impressões de sua infância, e muito especialmente as recebidas nos primeiros anos" (FREUD, 1900, p. 215).

Freud afirmou isso no percurso de suas pesquisas na área da Psicanálise, onde, possibilitou ao mundo uma nova maneira de compreender a espécie humana, reflexões a partir da fala anatômica corpo-alma. As descontinuidades do ser, faz parte dos elementos de sua constituição, a humanidade é inconclusa, evolui ao longo do tempo e do espaço natural, adquire experiências, acumulando e retroprojetando novas concepções.

A vida é concebida pela troca constante de energias, nossa projeção corpórea está interligada ao cosmo, compreender as fronteiras do pensamento do homem é algo que necessita de reflexões sobre a consciência individual e coletiva dos indivíduos, dessa forma, o organismo mental infantil é um espaço que apresenta conceituações da realidade vinculadas às subjetividades do universo.

A fala, o desenho, a escrita, os gestos são formas de expor o pensamento, travessias que cruzam o campo da comunicação, produzem sonoridades que ecoam na natureza do ser. Ao cogitar na ótica infantil, as Representações Sociais da Natureza, buscamos associar as reminiscências do uno plural de forças que se conectam na tônica da construção humana onde,

\footnotetext{
Para nós, hoje, a natureza é o conjunto articulado de todas as energias cósmicas em processo de materialização e desmaterialização; são as infinitas probabilidades, irrompendo no vácuo quântico, abertas a concretização; é a complexidade da matéria sempre em interação; é a vida em sua unidade e diversidade de manifestações como processo de auto-organização (poiesis) da matéria; é o próprio logos universal; é cósmico se expressando na história e produzindo cultura, significações e processos de espiritualização. (BOFF, 2003, p. 36)
}

O fluxo da seiva que corre nas raízes da natureza humana comunica o eco que ressoa pelos sons da fala, os ares da linguagem mental, respiram as imagens latentes do pensamento, transpostas na face das representações em contato com o eu-outro, 


\section{Hem eutuarao

ISSN: 1984-6444 | http://dx.doi.org/10.5902/1984644433823

são partes que compõem o todo e se completam na floresta da imaginação humana. Assim, as ideias da mente infantil atravessam as águas da vida, são fluidos que irrigam as raízes da humanidade, desde a superfície até as profundezas de sua essência.

\section{Material e Métodos}

\section{Área de Estudo e participantes da pesquisa}

Esta pesquisa é de abordagem quali-quantitativa, pautada numa descriçãoanalítica das Representações Sociais infantis sobre Natureza. O desenvolvimento da pesquisa ocorreu, na Escola Municipal de Tempo Integral Iracema Pereira da Paixão, zona urbana e na Escola Municipal Eleotério da Fonseca, zona rural do município de Juazeiro-BA, o estudo foi desenvolvido nas turmas do $2^{\circ}$ ano do ensino fundamenta I, totalizando 51 crianças, com faixa etária de 7 a 10 anos.

\section{Instrumentos metodológicos}

Os procedimentos metodológicos utilizados para o desenvolvimento da pesquisa foram: observação participante, diário de campo, oficinas de mapa mental e entrevistas. Organizamos um cronograma para o desenvolvimento do estudo, buscando a condução de todas as etapas da pesquisa. Conversas, olhares e perguntas foram florescendo na atmosfera do ambiente escolar, nesse espaço de tempo, iniciamos as observações participantes, com a perspectiva de construir uma familiaridade com as crianças.

Organizamos e desenvolvemos quatro oficinas intituladas: O que é Natureza; Natureza em Juazeiro; O futuro da Natureza e a construção de uma História sobre a Natureza. Planejamos todo o passo-a-passo, organizando pastas individuais, com todo o material didático necessário, tais como: lápis, borracha, apontador, lápis de cor, canetas hidrocor e papel. Durante o desenvolvimento das oficinas realizamos entrevistas semiestruturadas com as crianças, buscando compreender as ilustrações e a evocação dos pensamentos sobre a Natureza. 


\section{Usm

ISSN: 1984-6444 | http://dx.doi.org/10.5902/1984644433823

\section{Procedimentos éticos para o desenvolvimento da pesquisa}

O projeto de pesquisa foi submetido ao Comitê de Ética em Pesquisa - CEP da Universidade do Estado da Bahia - UNEB, juntamente a Plataforma Brasil. Em diálogo com as escolas apresentamos à proposta da pesquisa a equipe escolar, coletando os termos de Coparticipantes. Após submissão e emissão do parecer de aprovação no: 2.152.824, emitido pelo CEP, apresentamos o projeto de pesquisa para as crianças e endereçamos os Termos de Consentimento Livre e Esclarecido - TCLE para os pais e responsáveis, bem como, os Termos de Assentimento do Menor - TAM.

\section{Análise dos Dados}

No âmbito da coleta e análise dos dados, o desenvolvimento das oficinas inspirou-se no método psicanalítico freudiano de "associação livre", onde, de maneira fluida e reflexiva as crianças, a partir da temática central das oficinas representavam, por meio de desenhos, as "ideias latentes", penetrando nas raízes dos pensamentos através dos desenhos e da fala (FREUD, 1900). Após a finalização dos desenhos, realizamos uma breve entrevista semiestruturada, perguntas que cogitavam sobre a composição dos elementos do desenho e sobre a temática da oficina.

Analisamos a composição dos desenhos a partir dos ícones ilustrados, organizando uma tabela, que resultou no gráfico exposto na (figura 7 e 8). Para análise das representações, utilizamos a Análise de Conteúdo, uma imersão nos elementos ocultos, na fertilidade da mensagem do conteúdo latente, representados nos desenhos e no discurso infantil sobre Natureza, evocando assim aspectos que transcendem a materialidade das palavras e das ilustrações (BARDIN, 2016).

\section{Resultados e discussão}

\section{A Natureza da Natureza: imagens do conteúdo latente}

O universo apresenta uma imensidão de organismos vivos que interagem entre si, vidas que se une a outras vidas numa dimensão infinitamente ampla. A Terra apresenta uma sistemática de formas compostas de maneira diversa, cogitar sua pluralidade é refletir quão intensa é a vida. Assim, essas considerações nos levam a 


\section{Lusm oittrabat}

ISSN: 1984-6444 | http://dx.doi.org/10.5902/1984644433823

pensar que cada Representação Social apresenta um sentido, riscos e rabiscos, formas e desformas, expressa a origem de um sentido, pronuncia a fala mental em contato com o ambiente.

As raízes dessa relação é objeto de estudo da Ecologia Humana, ciência que estuda os fenômenos da natureza humana, as relações do homem com o ecossistema planetário. Vale a pena ressaltar, que em meio à confluência de conhecimentos científicos construídos ao longo dos anos,
A Ecologia humana hoje é entendida como uma ciência que estuda a natureza da humanidade numa perspectiva sistêmica e complexa, para além das fronteiras das disciplinas, e que não reduz o pensamento sobre a relação entre as pessoas e os ecossistemas a uma visão ingênua sobre as múltiplas dimensões da realidade humana. (MARQUES, 2014, p. 97)

A Natureza e o homem são energias que se cruzam numa conexão transcendental, cogitar a relação desses conhecimentos, é um campo de estudo que imerge na essência da união de forças que se propagam no interior da vida. Segundo Iva Pires a, "ecologia humana não é simplesmente uma especialização da ecologia, mas representa uma nova ciência que se desenvolveu nas lacunas de conhecimento das interdependências entre os sistemas sociais e naturais" (2011, p. 23).

A construção de uma representação tem início nos contornos da mente em contato com os fluidos do ambiente, a projeção de cada elemento que irá compor esse mapa mental, advém do cruzamento dessas fronteiras. Ao nos debruçarmos nas concepções trazidas pela teoria cartográfica da mente, imergimos numa série de fluxos de conhecimentos.

O mapa mental tem sua origem no conceito de "comportamento territorial", o pesquisador Tolman publicou em 1948 um artigo intitulado Cognitive maps in rats and men, discutindo também o significado desses achados ao comportamento humano (ANADÓN, 2003). Utilizamos a concepção de mapa mental discutida por Marta Anadón e Paulo Batista Machado, na obra intitulada Reflexões teórico-metodológicas sobre as representações sociais, para discutir a composição dos fenômenos mentais atrelados ao ambiente e suas especificidades no campo da Representação Social.

Nessa reflexão, pensar a conjuntura da mente é imergir num fluxo de inúmeras projeções, o labirinto mental humano é complexo, apresenta várias ramificações que se conectam a outras raízes do pensamento. Sendo assim, de acordo com Cossette, 


\section{工

ISSN: 1984-6444 | http://dx.doi.org/10.5902/1984644433823

Um mapa cognitivo é uma representação gráfica da representação mental que o pesquisador se faz de um conjunto de representações discursivas enunciadas por um sujeito a partir de suas próprias representações cognitivas, a respeito de um objeto particular. $(1994$, p. 13)

Tudo isso é muito dinâmico, e está ligado a uma série de movimentos que acontecem dentro e fora do corpo. Assim, como a luz solar radiada na Terra, as Representações Sociais propagam sua radiação imagética filtrada na atmosfera da mente, horizonte que reflete os tons multicolores desse incremento de informações, que se entrelaçam no espaço das ideias de cada indivíduo, em contato com saberes gerados na relação com o outro e com o mundo.

As figuras apresentadas abaixo são alguns dos desenhos realizados pelas crianças sobre Natureza, a partir das ilustrações realizamos a categorização dos ícones, apresentados nos gráficos 7 e 8 .

Figura 1 - Desenho da Natureza

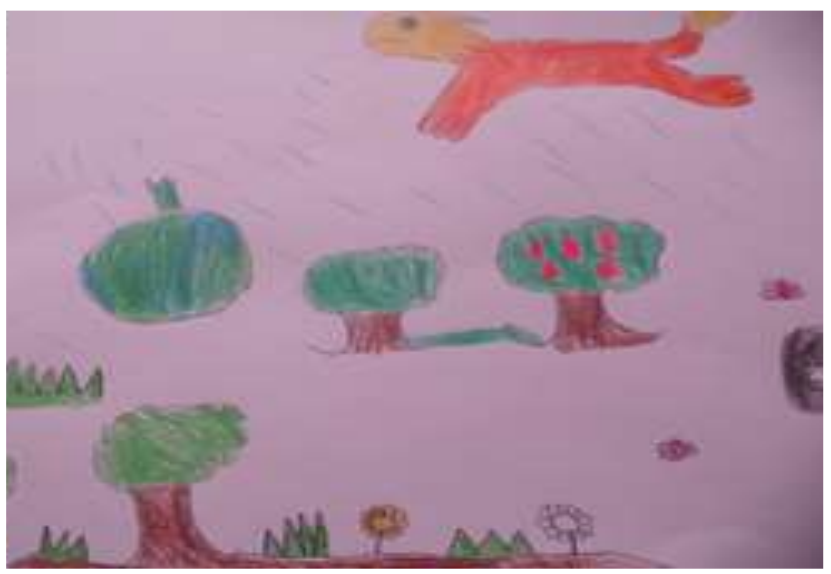

Fonte: (CRIANÇA S, 8 anos)
Figura 2 - Desenho da Natureza

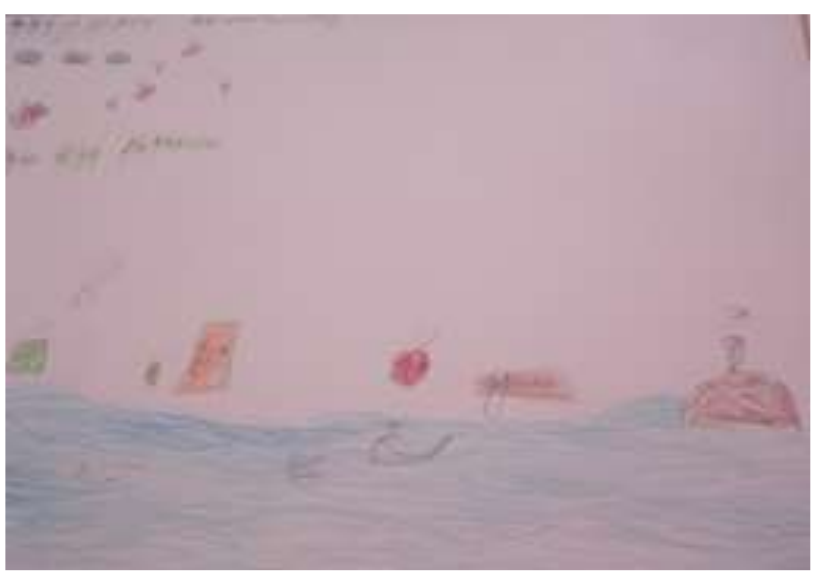

Fonte: (CRIANÇA R, 8 anos) 


\section{Hism Autlbarat}

ISSN: 1984-6444 | http://dx.doi.org/10.5902/1984644433823

tonalidades, traços e texturas, ordenados e desordenados, de maneira simples, mais ao mesmo tempo tão complexa.

Ao mesmo tempo que as coisas podem mudar, elas mantêm sua identidade, oculta em uma essência imutável. Assim, a água que flui nos rios transformase em nuvens e retorna ao solo como chuva; as sementes que viram árvores reaparecem nelas e, após um tempo, transformam-se em árvores mais uma vez. Mundos decaem e, dos seus restos, novos mundos emergem. A dança dos átomos anima a coreografia da Natureza. (GLEISER, 2014, p. 114)

Ao imergir, nos signos e significados das Representações Sociais infantis sobre a Natureza, percebemos uma série de movimentos, que se cruzam nos ares desse espaço. Na (figura 1) a criança relata sobre o grande espírito da Natureza, apresentando um conjunto de manifestações materializado no desenho e desmaterializada pela presença espiritual, ecoada na fala: "Eu desenhei a evolução da águia, como vai ser no futuro, pra mim ela significa o guardião do futuro, porque aqui mostra ela voando, vendo se tá acontecendo alguma coisa na Natureza. Eu penso que o futuro da Natureza vai ser assim, assim com borboletas, capim, pássaros, o guardião pra proteger a mata, eu não lembro o nome, mais é metade águia, e metade tem assas brancas, o Germano. Ele protege a Natureza, disso eu sempre soube. Ele espanta os predadores, ele espanta aqueles que faz mal a Natureza, com suas garras enormes, tem vez que ele voa atrás daqueles que querem matar os passarinhos, tipo com badoque, com arma, mas quem cuida da Natureza vem a primavera e fica tudo bom" (CRIANÇA S, 8 anos).

De acordo com Hutchison, "as perspectivas tanto cognitiva como afetiva/espiritual, a vida interna das crianças e sua experiência subjetiva do mundo emergem integrados à cosmologia da infância" (2000, p. 84). Percebemos nesse relato, a composição ascendente de um discurso, que se faz muito antes da exposição da fala, é nesse sentido que pensamos a tônica dos pensamentos infantis, entrelaçados a uma série de outros conhecimentos que vão evoluindo ao longo da vida.

Nesse sentido, o desenho expressa ilustrações que flutuam na mente, e se propagam pela memória de conhecimentos, evocados em contato com a Natureza, segundo Bédard, "o desenho representa, em parte, a mente consciente, mas também, e de uma maneira mais importante, faz referência ao inconsciente" (2013, p. 8). O 


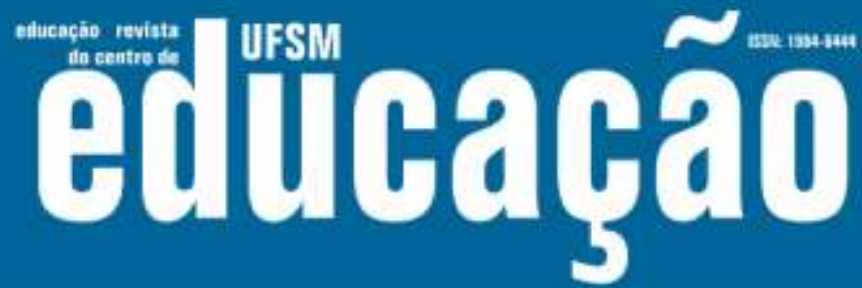

ISSN: 1984-6444 | http://dx.doi.org/10.5902/1984644433823

simbolismo das mensagens desenhadas se conecta com a explanação do pensamento no momento da fala sobre o desenho, é uma manifestação, transposta do pensamento para as imagens desenhadas.

$\mathrm{Na}$ (figura 2 e 6) percebemos a representação dos impactos antrópicos no rio São Francisco, as crianças registram o sentimento de tristeza pela poluição que aflige o rio, mas refletem também, sobre a mística do Nego D’água e a Mãe D'água, elas afirmam: "Eu valorizo muito as pessoas que não jogam lixo na rua, no mar e tudo mais, mas já algumas que jogam lixo no ambiente faz muito mal pra elas mesmo. Que o rio tá seco e com muito lixo dentro, e quando eu vou visitar o rio, quando eu vou lá no Nego D'água o Nego D’água tá na areia. Eu acho o Nego D’água seco muito triste, porque ele ficou muito seco e o rio bate até, um pouquinho mais longe do que ele, mas agora o rio tá mais longe dele, tá secando muito e é uma tristeza" (CRIANÇA R, 8 anos).

Ao questionar sobre a Mãe D’água, elas argumentam: "Significa muitas coisas, ela é legal, é bonita, tem calda grande, as escamas é tão bonitinha, ela nada, dá comida pros peixes, cuida da água, dá comida pro tubarão" (CRIANÇA V, 8 anos).

É importante refletir que na ótica das crianças algumas considerações, acerca dos impactos ambientais, aparecem relacionadas a uma onda de fatores, ou seja, elas refletem que tudo que é prejudicial à Natureza é nocivo ao ser humano. Percebemos também que alguns elementos, se interligam nas representações, aspectos vivenciados na atualidade, tais como, a seca e a poluição do rio São Francisco. Tudo isso é motivo de preocupação para as crianças, mas a espiritualidade aparece representada pela guardiã e guardião das águas, a Mãe D’água e o Nego D’água, vistos como entidades sagradas, protetores das águas do Velho Chico.

A (Figura 3) mostra o afeto, simbolizado pela figura do coração, sentimento bastante evocado na fala das crianças. Ao serem questionadas, elas dizem: "Um coração, porque eu gosto da Natureza, que eu amo a Natureza, as plantas, as árvores os pássaros, as nuvens" (CRIANÇA L, 8 anos). De acordo com Hutchison,

A criança se torna ligada a Terra no mais marcante dos sentidos, ricamente recompensada por uma multiplicidade de sensações impressionantes, paladares favoritos e observações guardadas com carinho que são lançadas no seu organismo para que ela as experencie. (2000, p. 114) 


\section{U usm

ISSN: 1984-6444 | http://dx.doi.org/10.5902/1984644433823

Ao analisar a (figura 4) percebemos o cuidado e respeito pelo meio ambiente, a criança simboliza também a relação matriarcal do homem com a Natureza, representada pela devolução da cobra a Natureza: "Porque isso dai é certo, é devolver a cobra, é e também a Natureza faz recompensa pra ele, por causa que o homem ele depois de um tempo, ele pegar esse negócio ai como agradecimento pra Natureza" (CRIANÇA S, 8 anos).

Nessa reflexão, percebemos a sensibilidade exposta na fala infantil. $O$ microbiologista René Dubos, na obra Um animal tão humano: como somos moldados pelo ambiente e pelos acontecimentos, apresenta algumas reflexões sobre a evolução do homem a partir da infância. Segundo o autor a ancestralidade das experiências vivenciadas no ambiente está articulada ao desenvolvimento humano.

A infância aponta o homem. Assim como a madrugada aponta o dia. Os versos valem como uma afirmação geral do fato, mas são também compatíveis com duas teorias inteiramente diferentes do desenvolvimento humano. Uma estabelece que as características da pessoa adulta são as expressões de sua hereditariedade e que já se notam durante sua infância e simplesmente continuam a desenvolver-se pelo resto da sua vida. A outra afirma que as experiências dos primórdios da vida moldam os atributos físicos e mentais da criança de maneira quase irreversível e determinam, portanto, o que o adulto será. A primeira teoria é identificada, geralmente, com a palavra "natureza" a segunda, com "educação". (DUBOS, 1974, p. 74)

Já na (figura 5) a criança representa a fala que excede o corpo das comunicações, o diálogo do homem com a Natureza, representam ecos de fala e escuta. Ao serem questionadas elas responderam: "Eu botei pessoas falando sobre a natureza, eu botei árvores, flores, sol. Uma coisa muito legal, um lugar divertido, calmo, onde a gente pode ouvir o som dos passarinhos" (CRIANÇA F, 8 anos). A escuta da Natureza é algo que transpõe a materialidade dos elementos, as ondas sonoras desse diálogo se cruza aos sons do canto dos pássaros, das águas, das folhas, dos animais, são Ecopercepções vivenciadas pelo corpo e pela alma humana.

A compreensão das Representações Sociais carregam elementos interpretativos que parte de alocuções mentais e sociais dos indivíduos, apresenta uma leitura muito peculiar. Assim, é necessário permear as raízes desse conteúdo, cada desenho expressa singularidades e pluralidades, conexa a outros elementos, a entrevista sobre os desenhos auxilia na intepretação e compreensão desses fatores, possibilitando refletir as tessituras dessas elaborações. Assim, 


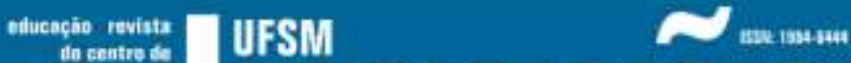

ISSN: 1984-6444 | http://dx.doi.org/10.5902/1984644433823

Através da observação atenta da natureza, do desenho de formas, dos estudos da geografia local, das investigações matemáticas e outros, as crianças devem começar a perceber gradativamente que os processos de integração e de diferenciação estão em operação continua no mundo inteiro, refletidos nas formas e nas funções da natureza como nas realizações artísticas e culturais dos seres humanos. (HUTCHISON, 2000, 148-149)

As elaborações desencadeadas na relação da criança com a Natureza, é uma construção concentradas em descobertas e inúmeras aprendizagens. Os resultados apresentados neste ensaio estão sistematizados, a partir da conjuntura dos processos investigativos.

Figura 7 - Percentual de ícones representados nos desenhos da Natureza na Escola Iracema

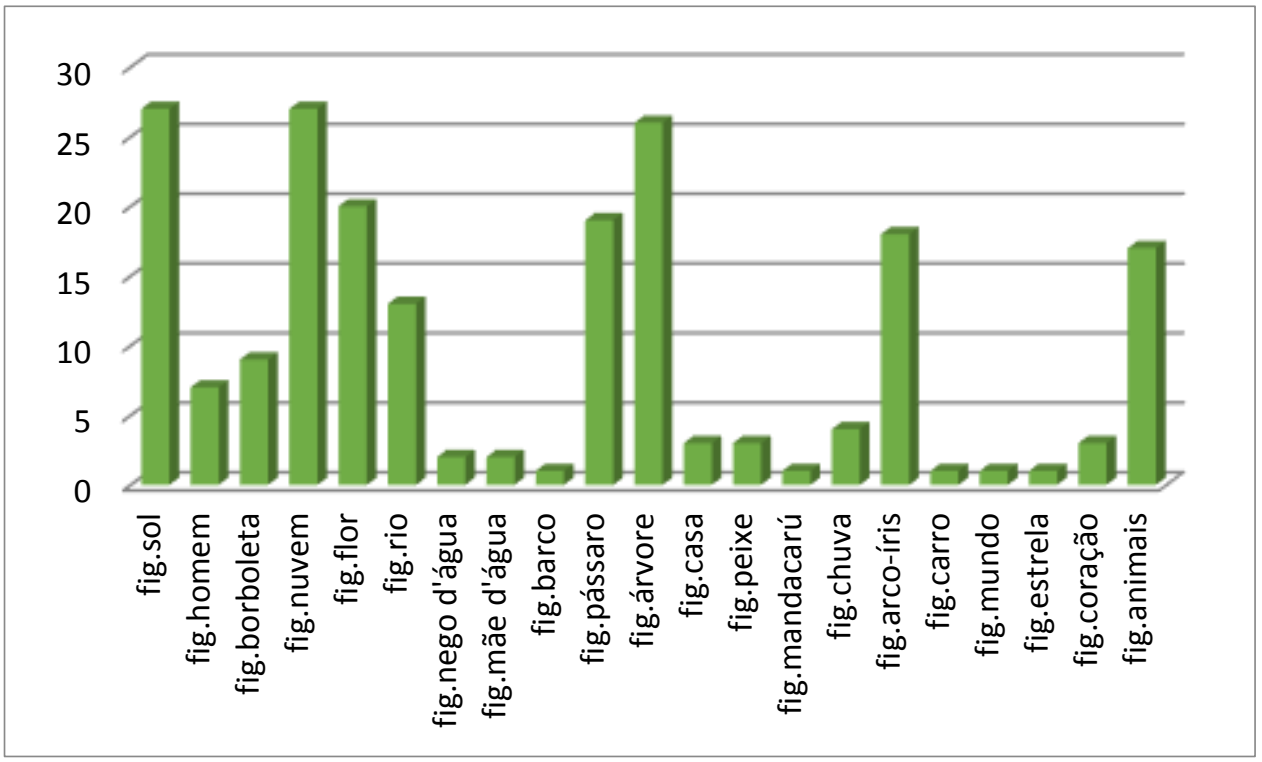

Fonte: (SILVA, 2017)

$\mathrm{Na}$ (figura 7) observamos a composição do quantitativo geral dos ícones ilustrados pelas crianças, percebemos que os elementos que aparecem com maior representatividade são: nuvem (27), sol (27), árvore (26), flor (20), pássaro (19), arcoíris (18), animais (17) e rio (13). Para compor esse gráfico, analisamos individualmente cada desenho, observando os elementos e registrando numa tabela. Dentro das 


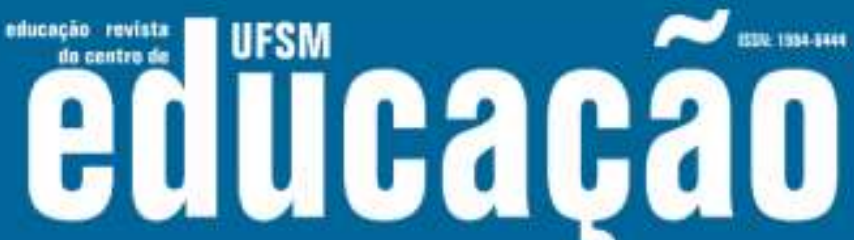

ISSN: 1984-6444 | http://dx.doi.org/10.5902/1984644433823

elaborações descritas nos desenhos, o sol é apresentado como protagonista das ilustrações infantis, seguido das nuvens e das árvores.

$\mathrm{Na}$ ótica infantil, o sol representa a energia do Sertão, pois, a partir das observações, percebemos que, na maioria dos desenhos, é o primeiro elemento a ser ilustrado. Segundo Bédard, o sol representa, "a energia masculina e define o nosso lado independente e combativo" (2013, p. 47). As nuvens trazem a sutileza e serenidade a energia solar, em alguns desenhos elas são representadas com a chuva. "A criança que é sensível ao ambiente costuma desenhar nuvens, o que denota que sua vida contém tanto momentos agradáveis como outros mais difíceis" (BÉDARD, 2013, p. 50).

A árvore também foi um ícone muito representado nos desenhos, ela é tida como o símbolo primordial da Natureza, as crianças concebem a árvore como elemento sagrado, responsável pela essência do ar que mantém a existência da vida. De acordo com Bédard, "a árvore foi sempre uma parte integrante da história do homem. Sob diferentes nomes, nós a encontramos em todas as religiões: "a árvore da vida", "a árvore do conhecimento", "a árvore do fruto proibido"” (2013, p. 52).

Ao questionar o que é Natureza? Eles responderam: "É nossa vida! Porque se não fosse a natureza nós não seria nada, as árvores trás o ar limpo pra nós, e se não fosse as árvores nós tava com calor" (CRIANÇA E, 9 anos). "Natureza pra mim é amor, amor, alegria, felicidade, e muitas coisas. Eu diria que a natureza significa pra mim, como se fosse meu pai e minha mãe cuidando de mim, ela representa amor" (CRIANÇA S, 8 anos). "A natureza pra mim é uma verdade, uma esperança, e o presente" (CRIANÇA, K, 8 anos).

O rio São Francisco aparece na representação das crianças com muita intensidade, ele expressa a nutrição da vida, pois a água vivifica a existência, e em alguns desenhos está associado à figura do Nego D’água e da Mãe D’água, descrito pelas crianças como protetores, guardiões das águas do Velho Chico. Ao perguntar o que a Mãe D’água e o Nego D’água representam, elas responderam: “A Mãe D'água dá alimento para os peixes, não deixa poluir o rio, o açude, pra deixar os rios limpos, pros peixes não morrer" (CRIANÇA I, 7 anos). "Representa o cuidador das águas. Eu 


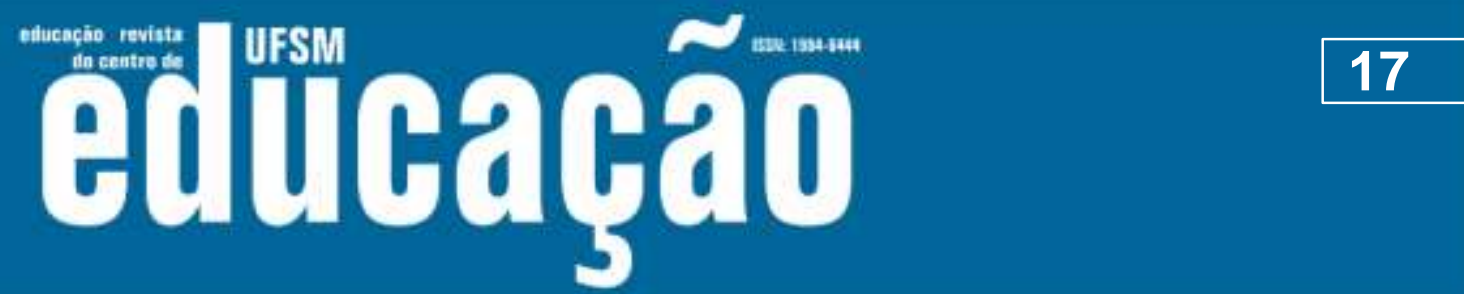

ISSN: 1984-6444 | http://dx.doi.org/10.5902/1984644433823

não sei, às vezes ele, eu penso que quando alguém tá gastando água ele não deixa" (CRIANÇA Y, 8 anos).

Mas, além disso, as crianças falam sobre a degradação ambiental, e argumentam sobre a seca do rio São Francisco e a série de impactos antrópicos causados ao longo dos anos. Elas argumentam: "Porque nos humanos, a gente tá destruindo a água, é eu não sei, é porque tem muita gente que quando o rio tava muito cheio ficava falando, há o rio não vai acabar nunca, que o rio é muito grande, que o rio não vai acabar nunca, ai eu não achei isso, porque tem gente que tá gastando muita água. Porque às vezes muitas pessoas fala: esse rio nunca vai secar porque ele tá muito cheio, e eu fiquei preocupada, por isso em todos os desenhos eu tô desenhando o rio e o Nego D’água" (CRIANÇA Y, 8 anos). Percebemos a sensibilidade das crianças ao reportar as ações instituídas pelos seres humanos, Cobb argumenta que,

$\mathrm{Na}$ infância, o processo cognitivo é essencialmente poético, porque é lírico, rítmico e formador em um sentido produtivo; é uma integração sensorial da própria criança a seu ambiente. A criança "conhece" ou reconhece nesses momentos que ela faz seu próprio mundo e que seu corpo é um instrumento sem igual, no qual os poderes da natureza e da natureza humana se encontram" (1977, p. 89)

Apesar da baixa representatividade do ser humano, na categorização dos ícones, exposto nas figuras 7 e 8, as crianças apresentaram durante as entrevistas, suas concepções sobre essa ocorrência, ao questioná-las sobre isso, elas responderam: "Eu vejo animais, cavalo e bichos, é muito bom, porque é muito bonita, eu vejo meus olhos, eu vejo minha vida" (CRIANÇA A, 8 anos). As crianças apresentam seus pensamentos, com maior destaque para os outros elementos da Natureza, mas, refletem também sua existência ligada a ela, concebendo a Natureza como o princípio de tudo, inclusive dos seres humanos.

As reflexões das crianças se conectam a outras questões, que estão enraizadas na história da humanidade, nesse ponto, podemos refletir sobre o espaço deixado pela trajetória revolucionária do mundo, marcada por regressos e evoluções socioambientais. A Ecologia Humana é uma ciência transdisciplinar que estuda o fenômeno humano, cogitar a estrutura desse processo, imerge na cíclica dos sistemas naturais, culturais e humanos, dentro e fora do ambiente escolar. Refletir sobre isso 


\section{Us: Aullatâ}

ISSN: 1984-6444 | http://dx.doi.org/10.5902/1984644433823

é de suma importância, pois, esta pesquisa mostra a necessidade de vincular mais nos processos educativos a relação da humanidade com a Natureza. As crianças ainda destacam nos desenhos e no discurso as ações antrópicas que degradam o meio ambiente, pensamentos vinculados a reflexões de um mundo melhor. Segundo Bérdad, "Na maioria dos casos, a figura humana representa própria criança, ou melhor, aquelas pessoas que compõem o seu ambiente mais íntimo" (2013, p. 45). A criança transporta para o desenho as imagens de seus pensamentos, em alguns desenhos elas se representam brincando em meio a Natureza, e em outros, fazem referência a humanidade de maneira geral.

Nesse sentido percebemos que a criança não coloca o homem em primeiro plano, o homem aparece como um elemento do meio ambiente, um organismo interligado a Natureza. As crianças argumentam: "Eu botei pessoas falando sobre a Natureza, eu botei árvores, flores, sol. Uma coisa muito legal, um lugar divertido, calmo, onde a gente pode ouvir o som dos passarinhos" (CRIANÇA MF, 8 anos).

Elas refletem nesse dialogo relações de cuidado, afeto e respeito pela Natureza, atribuindo sentimentos aflorados ao lugar habitado, fazendo referência a elementos presentes na escola, em casa, no bairro, na cidade, no planeta.

Figura 8 - Percentual de ícones representados nos desenhos da Natureza na Escola Eleotério

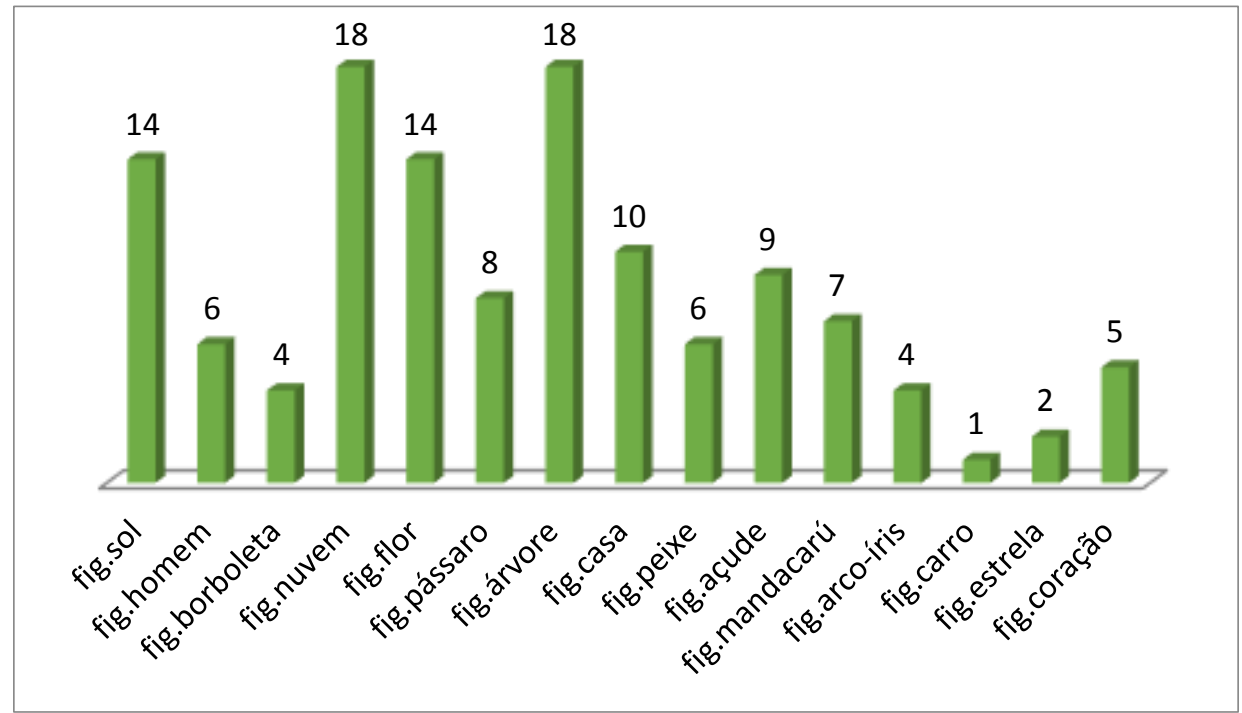

Fonte: (SILVA, 2017) 


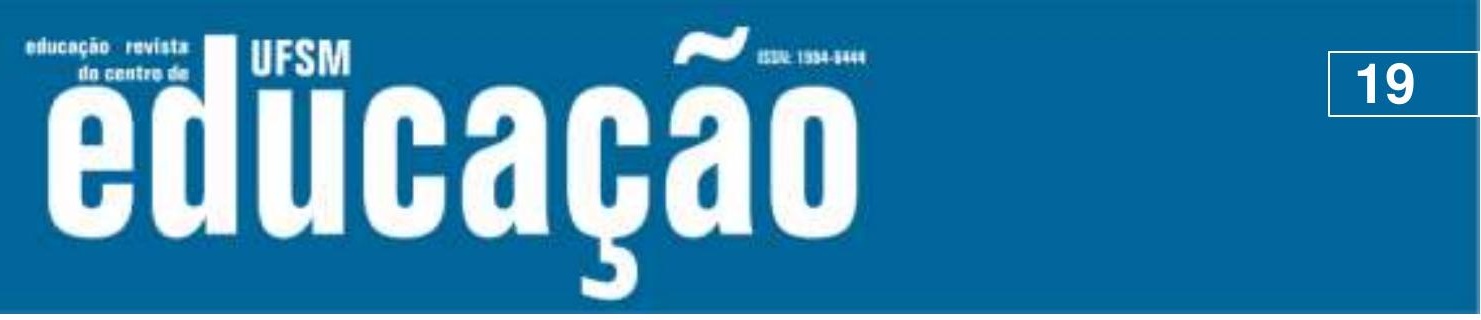

ISSN: 1984-6444 | http://dx.doi.org/10.5902/1984644433823

As concepções trazidas pelo olhar infantil sobre a Natureza, apresentado na (figura 8), expõem os elementos que aparecem com mais destaque nos desenhos, as figuras com maior representatividade são: árvore (18), nuvem (18), flor (14) e sol (14).

Ao questionar o que é Natureza? Elas disseram: "Eu gosto da Natureza, gosto de brincar na sombra. A Natureza pra mim é como se fosse cuidando de mim. Por causa que eu gosto da Natureza, eu amo a natureza. Quando eu tô brincando eu sinto que eu tô se ligando a Natureza" (CRIANÇA S, 8 anos).

No relato fica evidente a relação de cuidado e respeito pela Natureza, das ligações que se faz presente pelas brincadeiras, pelo aprendizado da vida que os cercam, suas percepções se cruzam no cotidiano, a partir das relações construídas com o ambiente. A percepção infantil apresenta conexões num fluxo profundo, observações concentradas na fertilidade da realidade e da subjetividade, são Ecopercepções sentidas nessa relação. A imensidão de vidas existentes na Natureza ultrapassa na nossa percepção, é algo que antecede nossa existência, porque,

\begin{abstract}
Quando caminhamos em meio a Natureza o que vemos são sistemas vivos. Em primeiro lugar, todo organismo vivo, da mais minúscula bactéria a todas as variedades de plantas e animais, incluindo os seres humanos, é um sistema vivo. Em segundo lugar, as partes dos sistemas vivos são, elas próprias, sistemas vivos. Uma folha é um sistema vivo. Um musculo é um sistema vivo. Cada célula do nosso corpo é um sistema vivo. E em terceiro, as comunidades de organismos, que incluem tanto os ecossistemas e os sistemas sociais humanos como a família, a escola e outras comunidades humanas são sistemas vivos. (CAPRA, 2006, p. 48)
\end{abstract}

As crianças tem uma sensibilidade perceptiva aguçada, vejamos esse relato: "Quando meu irmão planta uma semente, eu planto uma semente, mas quando demora nascer, quando passa um ano ela não nasce. Quando não nasce eu pergunto a David, David se uma semente não nasce ela está podre? Então ele responde: "Sim! Mas tem uma coisa que eu sei que quando uma planta se liga a Natureza, eu acho que a Natureza tá cuidando da plantinha, para poder a plantinha cuidar de outra plantinha que vai nascer. Mas então eu penso que se a gente cuidar da Natureza Deus pode dá uma vida melhor pra gente, porque a gente só sofre, quando a gente está descuidando da Natureza. Só jogando lixo na Natureza, ai Deus castiga as pessoas. Então se um dia a gente reconhecer o que tá acontecendo, eu queria falar aqui, quando alguma coisa acontecer de ruim, queria falar pra todos para que aprenda essa 


\section{Autuaŗão}

ISSN: 1984-6444 | http://dx.doi.org/10.5902/1984644433823

lição, com muito bom gosto, aprender a cuidar da Natureza e um dia a Natureza pode recompensa-los, e cuidar das pessoas como elas cuidam das plantinhas" (CRIANÇA S, 8 anos).

Fica nítido o elo afetivo, as palavras e os desenhos comunica sua visão: "Natureza pra mim é uma alegria, que deixa todo mundo feliz e eu não gosto que faça maldades com a natureza, isso não se faz. Porque a mãe natureza não gosta disso, pode tirar nossas vidas e destruir nossas casas, nossos lugares e nossos prediletos lagos e nossas águas, que a gente tem que beber pra ficar vivo e a gente tem que sobreviver com água se não a gente pode, de repente, aparecer a mãe natureza e colocar um castigo na gente" (CRIANÇA N, 8 anos).

A Ecopercepção vai ao encontro à visão ecológica do mundo, possibilita uma reflexão dos aspectos socioambientais que estão inseridos nesse processo. Perceber o mundo de maneira ecológica, é visualizar a sistemática da vida pelos princípios que nos liga a ela, envolve elementos sinestésicos, mas também os aspectos sociais, econômicos, éticos, políticos (DIAS, 2004).

A ecopedagogia pretende desenvolver um novo olhar sobre a educação, um olhar global, uma nova maneira de ser e de estar no mundo, um jeito de pensar a partir da vida cotidiana, que busca sentido a cada momento, em cada ato, que "pensa a prática" (Paulo Freire), em cada instante de nossas vidas, evitando a burocratização do olhar e do comportamento" (GADOTTI, 2000, p. 82).

A reflexão desse processo faz-se a partir do envolvimento, consciência e inconsciência se cruzam nas camadas do pensamento humano, é um Eco que comunica ao outro e ao mundo o verdadeiro sentido da vida. Sendo assim, a "percepção é tanto a reposta dos sentidos aos estímulos externos como a atividade proposital na qual certos fenômenos são claramente registrados, enquanto outros retorcem para a sombra ou são bloqueados" TUAN, 2012, p. 18).

As experiências do dia-a-dia estão interligadas ao discurso das crianças, elas relatam também sobre suas vivencias: "Daquela vez, quando eu ia pra Quichabeirinha, minha roça, tem plantação, tem bicho, tem cavalo, milho, melão, melancia, não tem aquelas melancia pequenininha, melancia da praia, você já comeu uma vez? Planta também lá, as pirralhas, minhas primas, a mamãe o papai e minha tia. Eu acho muito bom, porque a gente come, você sabe né, essas coisas, ai eu acho 


\section{Autuaŗão}

ISSN: 1984-6444 | http://dx.doi.org/10.5902/1984644433823

muito bom plantar coisas, pra poder fazer as plantinhas crescer, ai eu acho bom isso, dá comida aos cavalos. Ajudar os animais, porque tem ovelhas que já morreram na roça, porque eu fui pra viajar, eu ficava todo indo na roça, ai eu fui viajar, eu acho que elas duas sentiram falta de mim, eu criava elas desde de pequenininha, na hora que eu me sentei no chão elas, chega foi pra cima de mim, me lambendo, não tem aquelas ovelhas que quando a gente chega perto corre, após elas corriam. Abracei, tão fofinha, dei carinho, eu senti boa, peguei nela e vi que ela tava com uma mordida, ai eu dei um remédio, ai no outro dia ela amanheceu morta" (CRIANÇA L, 9 anos).

As ilustrações categorizadas pelo olhar infantil vão além de classificações puramente materiais, imergem numa atmosfera ultrassensível de ideias que transcendem o aparente, adentrando nas fronteiras do conteúdo latente por trás dessas representações.

\section{Considerações Finais}

$\mathrm{Na}$ atualidade, a Terra pronuncia o chamamento para a união de forças em prol da Natureza, entendemos que é pertinente, discutir a partir da ótica da criança, suas percepções e representações sobre a Natureza. Nesse universo, é de suma importância refletir as evocações trazidas à tona pelas expressões infantis, buscando aflorar no interior das relações uma postura ética, que interligue saberes sociais e naturais.

Esta pesquisa buscou refletir quão sensível são as cogitações infantis sobre a Natureza, permear esse universo é uma possibilidade de penetrar nas fronteiras do conhecimento humano e natural, saberes que desde então é campo de estudo da Ecologia Humana.

Apesar da ocorrência de representações humanas nos ícones infantis, tanto na escola rural como na urbana, é importante vincular mais nos processos educativos de que os humanos não se desvinculam da Natureza que aparece reforçada pelas plantas, bichos, nuvens, arco-íris, etc. O universo infantil é o início do desenvolvimento humano, que vai evoluindo ao longo do tempo, essas reflexões são de suma importância, para a construção de uma filosofia de vida pautada na ética e na sustentabilidade planetária. 


\section{T Wusm eutuaráo}

ISSN: 1984-6444 | http://dx.doi.org/10.5902/1984644433823

As Representações Sociais da Natureza na visão infantil, nos faz refletir sobre a ocorrência das ações antrópicas que prejudicam a Natureza, a construção de novos caminhos, em busca de um mundo melhor. Ser e estar nesse planeta desabrocha outros sentidos, são significados que emergem de Ecopercepções, questões que ultrapassam as categorias da materialidade, imergindo nas raízes da atmosfera transcendental e da Natureza.

A origem dessa relação se inicia na infância, na pequenez do homem enquanto criança. A Natureza da Natureza está presente dentro e fora do corpo humano, é falar e escutar a língua da Natureza. E se um dia o homem, a mulher, já foram criança, que a criança que habita o seu interior possa ouvir e falar para o mundo o verdadeiro sentido da vida, principiado num elo ético, de cuidado, respeito e afeto pela Terra.

\section{Referências}

ANADÓN, Marta. Reflexões teórico-metodológicas sobre as representações sociais / Marta Anadón. Paulo batista Machado. - Salvador: editora UNEB, 2003.

BARDIN, Laurence. Análise de Conteúdo. Portugal: Edições 70, 2016.

BÉDARD, Nicole. Como interpretar os desenhos das crianças / Nicole Bédard / $1^{\text {a }}$ edição/ São Paulo, SP / Editora Isis, 2013.

BOFF, Leonardo. Ethos Mundial / Leonardo Boff. - Rio de Janeiro: Sextante, 2003.

BRONFENBRENNER, Urie. A ecologia do desenvolvimento humano: experimentos naturais e planejados. Artmed Editora Ltda. São Paulo, 1994.

CAMPOS, Dinah Martins de Souza. O teste do desenho como instrumento de diagnóstico da personalidade: validade, técnica de aplicação e normas de interpretação. 37ª edição, Editora: Vozes, Petrópolis, 2005.

CAPRA, Frijoft. Alfabetização ecológica: a educação das crianças para um mundo sustentável / Michael K. Stone e Zenobia Barlow, orgs ; prólogo David W. Orr ; prefacio Fritjot Capra ; prefacio à edição brasileira Mirian Duailibi ; tradução Carmen Fischer. São Paulo: Cultrix, 2006.

COBB, Edith. The ecology of imaginantion in childhood. Em D. McKinley \& P. Shepard (Eds.), The subversive science. Essays toward an ecology of man (p.122- 


\section{Tusm}

132), Boston: Hougthton Mifflin, 1969. Disponível em: https://books.google.com.br/books. Acesso em: 7 fev. 2018.

DI LEO, Joseph H. A interpretação do desenho infantil. Trad. De Marlene Neves Strey. Porto Alegre, Artes Médicas, 1985.

DIAS, Genebaldo Freire. Ecopercepção: um resumo didático dos desafios socioambientais, Editora: Gaia, 2004.

FREUD, Sigmund. Novas Conferências Introdutórias sobre Psicanálise. In: FREUD, S. Edição standard brasileira das obras psicológicas completas de Sigmund Freud. v. 22. Rio de Janeiro: Imago, 1990.

FRUTIGER, Adrian. Sinais e Símbolos: desenho, projeto e significado / Adrian Frutiger; tradução Karina Jannini. - São Paulo: Martins Fontes, 1999.

GADOTTI, Moacir. Pedagogia da terra / Moacir Gadotti; prefácio Ângela Antunes; apresentação José Eustáquio Romão; leituras e questões para aprofundamento Gustavo Cherubine e Natalia Bernal. - São Paulo; Peirópolis, 2000.

GLEISER, Marcelo. A ilha do conhecimento [recurso eletrônico]: os limites da ciência e a busca por sentido / Marcelo Gleiser. - 1. ed. - Rio de Janeiro: Record, 2014.

HUTCHISON, David. Educação ecológica: ideias sobre consciência ambiental / David Hutchison; trad. Dayse Batista. - Porto Alegre: Artes Médicas Sul, 2000.

MARKOVÁ, Ivana. Dialogicidade e representações sociais: as dinâmicas da mente / Ivana Marková; tradução de Hélio Magri Filho. - Petrópolis, RJ: Vozes, 2006.

MARQUES, Juracy. Ecologias Humanas. Juracy Marques (org.). Feira de SantanaBA UEFS, 2014.

MARQUES, Juracy. A Ecologia de Freud: os Ecossistemas da Natureza Humana. Paulo Afonso: SABEH, 2017.

MOSCOVICI, Serge. A representação Social da Psicanálise. Tradução de Álvaro Cabral, Zahar Editores, Rio de Janeiro, 1978.

PARK, Robert Erza. Human Ecology. In: The American Journal of Sociology, XLII/1, 1936.

PIAGET, Jean. A representação do mundo da criança: com o concurso de onze colaboradores / Jean Piaget; tradução Adail Ubirajara Sobral (colaboração de Maria Stela Gonçalves). - Aparecida, SP - Ideias \& Letras, 2005. 


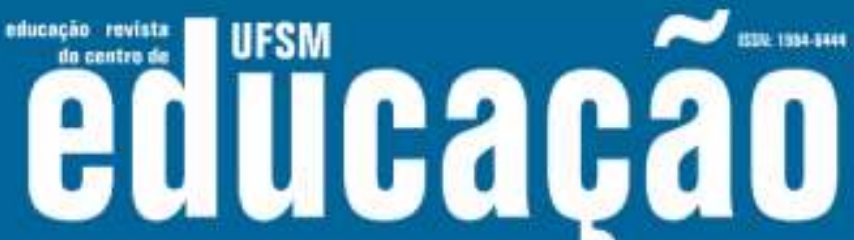

ISSN: 1984-6444 | http://dx.doi.org/10.5902/1984644433823

PICKERING, W. S. F. Introducion. In. PICKERING, W. S. F. (ed.). Durkheim and representations. Londres: Routledge: Londres, p. 1-8, 2000. Disponível em: https://philpapers.org/rec/PICDAR. Acesso em: 13 fev. 2018.

PIERSON, Donald. Estudos de Ecologia Humana. São Paulo: Martins Editora, 1945.

PIRES, Iva Miranda. Ética e Prática da Ecologia Humana: Questões Introdutórias sobre a Ecologia Humana e a Emergência dos Riscos Ambientais. Lisboa: APENAS, 2011.

TUAN, Yi-Fu. Topofilia: um estudo da percepção, atitudes e valores do meio ambiente. São Paulo/Rio de Janeiro. Difel. 1980.

\section{Correspondência}

Daniela Santos Silva - Professora do Instituto Federal de Educação, Ciência e Tecnologia Baiano, Bahia, Brasil.

Juracy Marques dos Santos - Professora titular da Universidade do Estado da Bahia (UNEB), Salvador, Bahia, Brasil.

Instituto Federal de Educação, Ciência e Tecnologia Baiano - Campus Senhor do Bonfim. Estrada da Igara, s/n - Zona Rural, Senhor do Bonfim. CEP: 48970-000, Senhor do Bonfim, Bahia, Brasil.

Universidade do Estado da Bahia, Programa de Pós-graduação em Ecologia Humana e Gestão Socioambiental. Av. Edgard Chastinet Guimarães, s/n, São Geraldo. CEP: 48904-711, Juazeiro, Bahia, Brasil.

E-mail: sdan.santos@gmail.com - juracymarquespshy@gmail.com

Recebido em 20 de julho de 2018

Aprovado em 31 de outubro de 2018

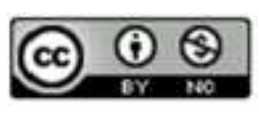

This work is licensed under a Creative Commons Attribution-NonCommercial 4.0 International (CC BY-NC 4.0) 